\title{
Mammographic profiles of women with symptomatic breast diseases in Port Harcourt, Rivers State, Nigeria.
}

\author{
*Onwuchekwa R.C. ${ }^{1}$, Alazigha N.S. ${ }^{2}$
}

\begin{abstract}
Objectives: Most patients with breast lesions are usually anxious especially with the knowledge that breast cancer is associated with high rate of mortality and morbidity. The aim of this study is to evaluate the characteristics of breast lesion as depicted by mammography in women with symptomatic breast diseases.
\end{abstract}

Methods: This was a prospective descriptive analytical study of women with symptomatic breast diseases who had mammography between January 2012 and December 2016 at our health facilities. Data sheet was developed to record the patients' biodata, indication for referral, and mammographic findings.

Results: During the period of study, 166 females with symptomatic breast lesions had diagnostic mammography. The mean age was 49.29years \pm 11.12 . Sixty- five $(39.2 \%)$ patients presented with breast lump, 54(32.5\%) had breast pain, while 15 (9.0\%) had nipple discharge.

Seventy- five $(45.2 \%)$ of the patients had no obvious lesion on mammogram, while $91(54.8 \%)$ had identifiable lesions. The masses were multiple in $9(12.7 \%)$, diffused in $4(5.6 \%)$ and solitary in 58 $(81.7 \%)$. Six (3.6\%) cases were found to have only calcifications. BI-RADS category 1 was the most prevalent constituting 75(45.2\%). This was followed by BI-RADS categories $3 \& 4$, each constituted 30 $(18.1 \%)$ cases.

Conclusion: Breast diseases are common in our environment and this review had shown that most of these lesions were benign. Breast lumps and breast pains were the commonest indication for the mammograms and significant number of the patients had no demonstrable lesions on mammogram. BIRADS category 3 and 4 were more common.

Key words: Breast, mammography, BI-RADS, benign, malignant, lump, pain.

\footnotetext{
*Correspondence author

Onwuchekwa R.C. (Ph.D)

http://orcid.org/0000-0002-5870-0486

Email: chichekwas2003@yahoo.com
}

${ }^{1}$ Department of Radiology, Faculty of Clinical sciences, College of Health Sciences, University of Port Harcourt, Port Harcourt, Nigeria

${ }^{2}$ Department of Radiology, Braithwaite Memorial Specialist Hospital, Port Harcourt, Nigeria

\footnotetext{
Research Journal of Health Sciences subscribed to terms and conditions of Open Access publication. Articles are distributed under the terms of Creative Commons Licence (CC BY-NC-ND 4.0). (http://creativecommons.org/licences/by-nc-nd/4.0).

http://dx.doi.org/10.4314/rejhs.v5i4.2
} 


\title{
Profils mammographiques de femmes présentant des maladies mammaires symptomatiques à Port Harcourt, Etat de Rivers, Nigéria.
}

\author{
*Onwuchekwa Regina C. ${ }^{1}$, Alazigha Nengi S. ${ }^{2}$
}

\section{Resume}

Objectif: La plupart des patients présentant des lésions mammaires sont généralement anxieux, sachant que le cancer du sein est associé à un taux élevé de mortalité et de morbidité. Le but de cette étude est d'évaluer les caractéristiques de la lésion mammaire telle que décrite par la mammographie chez les femmes présentant des maladies mammaires symptomatiques.

Méthodes: Il s'agissait d'une étude analytique descriptive prospective des femmes atteintes de maladies mammaires symptomatiques qui ont eu une mammographie entre janvier 2012 et décembre 2016 dans nos établissements de santé. Une fiche de données a été élaborée pour consigner les données biographiques des patients, les indications de référence et les résultats des mammographies.

Résultats: $\mathrm{Au}$ cours de la période d'étude, 166 femmes présentant des lésions mammaires symptomatiques ont eu une mammographie diagnostique. L'âge moyen était de 49,29 ans $\pm 11,12$. Soixante-cinq $(39,2 \%)$ patients présentaient une grosseur mammaire, $54(32,5 \%)$ présentaient des douleurs mammaires, tandis que $15(9,0 \%)$ présentaient un écoulement mamelonnaire.

Soixante-quinze $(45,2 \%)$ des patients n'avaient pas de lésion évidente à la mammographie, tandis que 91 $(54,8 \%)$ avaient des lésions identifiables. Les masses étaient multiples chez $9(12,7 \%)$, diffusées chez 4 $(5,6 \%)$ et solitaires chez $58(81,7 \%)$. Six $(3,6 \%)$ cas ont été trouvés pour avoir seulement des calcifications. BI-RADS catégorie 1 était le plus répandu constituant 75 (45,2\%). Cela a été suivi par BIRADS catégories 3 et 4 , chacun constituait 30 cas $(18,1 \%)$.

Conclusion: Les maladies du sein sont courantes dans notre environnement et cette revue a montré que la plupart de ces lésions étaient bénignes. Les grosseurs de poitrine et les douleurs mammaires étaient les indications les plus courantes pour les mammographies et un nombre significatif de patientes n'avaient pas de lésions démontrables à la mammographie. BI-RADS catégories 3 et 4 étaient plus fréquents.

Mots clés: Sein, mammographie, BI-RADS, bénin, malin, forfaitaire, douloureux.

*Correspondence auteur

Onwuchekwa R.C. (Ph.D)

http://orcid.org/0000-0002-5870-0486

Email: chichekwas2003@yahoo.com

${ }^{1}$ Department of Radiology, Faculty of Clinical sciences, College of Health Sciences, University of Port Harcourt, Port Harcourt, Nigeria

${ }^{2}$ Department of Radiology, Braithwaite Memorial Specialist Hospital, Port Harcourt, Nigeria

Research Journal of Health Sciences subscribed to terms and conditions of Open Access publication. Articles are distributed under the terms of Creative Commons Licence (CC BY-NC-ND 4.0). (http://creativecommons.org/licences/by-nc-nd/4.0).

http://dx.doi.org/10.4314/rejhs.v5i4.2 


\section{INTRODUCTION}

Breast lesions are generally grouped into benign and malignant lesions of which the benign lesions are in the vast majority $(1,2,3)$. Commonly breast diseases are usually seen as cancer because, cancer is the most dreaded ailing condition of the breast. The fear of being diagnosed with breast cancer may be an encouraging or discouraging factor for undergoing mammographic evaluations in some of the patients. Most patients with breast lesions are usually anxious especially with the knowledge that breast cancer is associated with high rate of mortality and morbidity. Imaging is useful in reassuring the patient of a greater likelihood of the lesion being a benign condition than cancerous $(4,5)$.

In Nigeria, as in most developing countries of the sub - Saharan region, breast lesions are evaluated with mammography, ultrasonography or both. However, in the developed countries Magnetic Resonance Imaging (MRI) of the breast which is by far more sensitive (1), is utilized for both screening and diagnostic evaluation of the breast.

The advantages of mammography include its ability to depict subtle breast calcifications especially the micro-calcifications that may be associated with intra-ductal malignancy. It demonstrates non- palpable masses and can also be used to evaluate the marginal characteristics of breast masses. Its pitfall is in the evaluation of dense breast especially in young highly glandular breast. It may not detect the lesion accurately, in which case use of ultrasonography as an adjunct would yield a higher sensitivity.

The aim of this study is to evaluate the characteristics of breast lesion as depicted by mammography in women with symptomatic breast diseases who presented for diagnostic assessment in the two health institutions.

\section{MATERIALS AND METHODS}

This was a prospective descriptive analysis of women with symptomatic breast diseases who presented to the Radiology department of a specialist Private clinic in Port Harcourt and a government Specialist Hospital also in Port Harcourt for diagnostic mammography between January 2012 and December 2016, irrespective of age. Data obtained include patients' biodata, indications for referral, occupation of the patient and mammographic findings. We also collected data on additional mammography or ultrasound imaging following the diagnostic mammography where applicable.

The mammography machines used were METALTRONIC SRL. Manufactured by Via Della Pisana, 431-00163 Rome, Italy at the Specialist Private Clinic and General Electric (GE) Senographe DMR machine at the Government specialist general hospital. All the patients had their mammograms reviewed by a radiologist before leaving the department, (ORC and NSA at the private specialist hospital and government specialist general hospital respectively).

The mammographic findings were classified as benign or malignant according to the Breast Imaging Reporting and Data System (BIRADS) designed by the American College of Radiology (ACR) in 1992 to standardize reporting. For the purpose of this study, BI-RAD categories 1 is considered normal breast or negative finding, BI-RADS 2, \& 3 were assigned benign finding while BI-RADS categories $4 \& 5$ were assigned malignant findings. BI- RADS 0 was assigned inconclusive and requires further evaluation.

The ethical standard laid down in the declaration of Helsinki was applied in all data collection and all the patients used in the study provided informed consent. The institutional review board at each hospital approved the protocol.

The collected data was analysed using SPSS version 20. Frequency tables, pie charts and histogram were used to present the results.

The radiologist used the following American College of Radiologist BI-RADS six assessment categories:

Category 0- need additional imaging (an adjunct ultrasound evaluation is carried out on the patients on the same day)

Category 1- negative (normal breast).

Category 2- benign findings

Category 3- probably benign findings, short-term follow up mammogram advised

Category 4- suspicious abnormality, biopsy advised

Category 5- highly suggestive of malignancy with appropriate action advised.

\section{RESULTS}

During the period of study, 166 females with symptomatic breast lesions had diagnostic mammography. The mean age was $49.29 \pm 11.12$ years. The age distribution is shown in table 1 . 
The largest proportion of the study population was in the age range of 41-50 years which constituted $59(35.54 \%)$ patients. Those above 70 years were the least frequent $2(0.6 \%)$ patients.

The indications for the mammography are presented in Table 2. Some patients presented with multiple symptoms, which included combination of pain, lump, axillary lymph nodes and nipple discharge; but only the major complaints were listed. Sixty- five patients (39.2\%) presented with breast lump, 54 (32.5\%) patients had breast pain, while $15(9.0 \%)$ patients had nipple discharge. Of those with nipple discharge, $12(80 \%)$ were bloody while $3(20 \%)$ were milky.

The findings at mammography are presented in Table 3. Seventy- five (45.2\%) patients had no obvious lesion on mammogram, while 91(54.8\%) patients had lesions. Of those that had lesions, mass lesions were the commonest constituting $71(42.8 \%)$ cases. The masses were multiple in $9(12.7 \%)$, diffused in 4 $(5.6 \%)$ and solitary in $58(81.7 \%)$. There were 16 $(22.5 \%)$ cases with irregular or spiculated margins and $55(77.5 \%)$ case of circumscribed mass with regular margin. $2(2.8 \%)$ of the masses had dense calcification. Six (3.6\%) cases had only calcifications without mass, with microcalcifications and macro-calcifications constituting $3(50 \%)$ cases each.

The final BI-RADS assessment classification is shown in Table 4. BI-RADS category 1, normal finding was the most prevalent constituting $75(45.2 \%)$ cases. This was followed by BI-RADS categories $3 \& 4$, which were designated probably benign and suspicious finding respectively; each constituted $30(18.1 \%)$ cases. The least was BI-RADS category 5 which designated lesions that are highly suspicious of cancer and there were only $2(3 \%)$ cases.

\section{DISCUSSION}

Diagnostic mammography of the breast is a component of the triple breast assessment standard practices that comprised of clinical examination, imaging and histo/cytopathological sampling (6). Mammography had assumed a vital role in the management of breast diseases and cancer screening.

The indication for diagnostic mammography is variable as demonstrated in this study. The symptoms presented by the patients may or may not be associated with obvious mammographic breast lesions. These symptoms include breast pain, lump, swelling, mastitis, nipple discharge and generalized discomfort. In this study breast lump accounted for the highest indication for a mammogram and was closely followed by pain and then nipple discharge. This finding is in agreement with what had been reported previously in literatures $(6,7,8)$. Some studies had contrary opinion as pain was the more common symptom (9), however in such studies breast discharge was also found to be the third in frequency as depicted in the index study. Many of those who presented with nipple discharge in the index study, had bloody discharge and this was similar to the finding by other researchers (10).

In this study there were some patients who did not have lesions on mammogram in spite of the fact that they had symptoms, which required evaluation with mammography. However, those with lesions on mammogram are more in number, they constituted more than 50\% of the study population. This finding was not surprising as most breast lesions are likely to present with symptoms; and some of those whose clinical examination findings were not suggestive of serious lesion may not have been referred for mammogram. In similar studies in other parts of Nigeria the researchers noted that more breast lesions were found in mammography $(7,11)$. Studies where those for screening mammogram were included $(9,12,13)$, had more cases without lesion in their mammogram. In patients with abnormal mammogram, the commonest findings were mass lesions, which were seen in $42.8 \%$. Masses with benign features were the most prevalent, and were described as well circumscribed opacities with regular or smooth margins, some of which had surrounding halo. Of these benign lesions, the most frequently diagnosed were fibroadenoma, followed by breast cysts. Most breast lesions had been reported to be benign in previous studies $(1,2,3,14,15)$, this is in tandem with our finding which also reported that fibroadenoma of the breast was more prevalent than other breast lesions, though some studies had postulated other breast lesions such as fibrocystic diseases to be commoner (2). The characteristics malignant breast features we encountered in this study were dense breast mass with irregular, multilobular and spiculated margins which may be poorly defined. Some were associated with microcalcifications. This finding was supported by the report by Varela et al (16) which suggested that the border and the outer areas of masses contained the most valuable information for differentiating between benign and malignant 
masses.

BI-RADS category 1 was in higher proportion, as $45.2 \%$ of the patients had no lesion on mammogram. This was surprising as the commonest indication in this study was breast lump, in which case one would have expected a mass. However there were also many cases of breast pain which may not have required mammography but had to be investigated because of patient's anxiety, such cases may have contributed to the high rate of BI-RADS category 1 cases. For those with lesions in their mammogram, BI-RADS categories 3 and 4 were more common. This showed a slight deviation from the report in the study by Akande et al. (15), where BI-RADS 2 was more prevalent in patients with lesions on the mammogram. These findings in the index study and that of Akande et al. confirms that benign breast lesions are more common than malignant breast lesions.

Limitations: the major limitation in this study is our inability to follow up the patient for histological confirmation of the breast lesions as some of them were managed outside our health facilities.

\section{CONCLUSIONS}

Breast diseases are common and this study had shown that most of these lesions were benign. Breast lumps and breast pains were the commonest indication for the mammograms and significant number of the patients had no demonstrable lesions on mammogram. BIRADS classification enables reproducibility of lesion categorization and in this study BI-RADS category 3 and 4 were more common, confirming that majority of breast lesions were benign.

Acknowledgment: We acknowledge the staff of the radiology department of Braithwaite Memorial Specialist Hospital and Dr. Berepele R.O. for their assistance during the period of data collection.

Conflicts of interest: The authors declare no conflict of interest.

\section{REFERENCES}

1. Starvos AT, Thickman D, Rapp U, et al. Solid breast nodules: use of sonography to distinguish between benign and malignant lesion. Radiology. 1995; 196: 123-134.

2. Ochicha O, Edino ST, Mohammed AZ, Amin SN. Benign breast lesions in Kano, Nig J Surg Res. 2002; 24: 257-262.
3. Malik G, Waqar F, Buledi GQ Sonomammography for evaluation of solid breast masses in young patients. J Ayub Med Coll Abbottabad. 2006; 18: 34-37.

4. Jumah KB, Obajimi MO, Darko R. Women with painful breasts without palpable masses: do they really need a mammogram? Afr J Med Med Sci. 2003; 32(4): 387-389.

5. Duijm LE, Guit GL, Hendricks JH, Zaat JO, Mali WP. Value of breast imaging in women with painful breasts: Observational follow up study. BMJ 1998; 317(7171): 1492-1495.

6. Biggs MJ, Ravichandran D. Mammography in symptomatic women attending a rapid diagnosis clinic. A prospective study. Ann R Coll Surg Engl 2006; 88: 306-308.

7. Akinola RA, Akinola OI, Shittu LAJ, Balogun BO, Tayo AO. Appraisal of mammography in Nigeria women in a new teaching hospital. Sci. Res. Essays 2007; 2(8): 325-329.

8. Ayoade BA, Tade AO, Salami BA. Clinical features and pattern of presentation of breast diseases in surgical outpatient clinic of a suburban tertiary hospital in south- west Nigeria. Niger J Surg. 2012; 18: 13-16.

9. Ozoilo KN, Misauno MA, Chukwuogo O, Ozoilo JU, Ojo EO, Yakubu AA. Breast cancer screening in a resource poor setting: A preliminary report. J Med Trop. 2014; 16: 14-18.

10. Ebubedike UR, Umeh EC, Anyanwu SNC, Ukah CO, Ikegwuonu NC. Pattern of mammography findings among symptomatic females referred for diagnostic mammography at a tertiary center in South-East Nigeria. West African Journal of Radiology 2016;23(1): 23-27

11. Eni UE, Ekwedigwe KC, Sunday- Adeoye I, Daniyan ABC, Isikhuemen ME. Audit of mammography requests in Abakaliki, SouthEast Nigeria. World Journal of Surgical Oncology. 2017; 15: 56. Doi 10.1186/s12957017-1122-1127.

12. Brakohiapa EK, Armah GE, Clegg-Lamptey JNA, Brakohiapa WO. Pattern of breast diseases in Accra; Review of mammography reports. Ghana Med J.2013; 47(3): 101-106.

13. Bello TO, Ojemakinde MO, Aremu AA, Ojemakinde KO, Agodirin SO. Screening mammography features in Nigerian women: a pilot study. Afri J Med Sci. 2012, 41

14. Irabor AO, Okolo CA. An audit of 149 consecutive breast biopsies in Ibadan, Nigeria. Pak J Med Sci 2008; 24: 257-262.

15. Akande HJ, Olafimihan BB, Oyinloye OI. A five year audit of mammography in a tertiary hospital, North Central Nigeria. Nigerian Medical Journal 2015; 56(3): 213-217.

16. Valera C, Timp S, Karssemeijer N. Use of border information in the classification of mammographic masses. Phys Med Biol. 2006; 51:425-441. 
Table 1: Age distribution of the study population

\begin{tabular}{lll}
\hline Age range & Frequency & Percentage \\
\hline $21-30$ & 7 & 4.22 \\
$31-40$ & 30 & 18.07 \\
$41-50$ & 59 & 35.54 \\
$51-60$ & 41 & 24.70 \\
$61-70$ & 26 & 15.66 \\
$>70$ & 2 & 1.20 \\
Unspecified & 1 & 0.60 \\
Total & 166 & 100 \\
\hline
\end{tabular}

Table 2. Frequency distribution of the indications for the breast mammogram

\begin{tabular}{lll}
\hline Indications & Frequency & Percentage \\
\hline Mastitis & 4 & 2.4 \\
Arm swelling & 1 & 0.6 \\
cyst & 7 & 4.2 \\
Cancer & 8 & 4.8 \\
Nipple discharge & 15 & 9.0 \\
Duct ectasia & 5 & 3.0 \\
Lump & 65 & 39.2 \\
Breast pain & 54 & 32.5 \\
Axillary lymph node & 1 & 0.6 \\
Ulcer & 1 & 0.6 \\
Previous lumpectomy & 2 & 1.2 \\
Breast swelling & 3 & 1.8 \\
Total & 166 & 100 \\
\hline
\end{tabular}

Table 3: Frequency distribution of mammography findings

\begin{tabular}{lll}
\hline Mammogram findings & Frequency & Percentage \\
\hline Normal & 75 & 45.2 \\
Mass lesions & 71 & 42.8 \\
Dense breast & 9 & 5.4 \\
Calcification & 6 & 3.6 \\
Intra-mammary lymph nodes & 3 & 1.8 \\
Skin thickening & 1 & 0.6 \\
Nipple retraction & 2 & 1.2 \\
scar & 2 & 1.2 \\
TOTAL & 169 & 100 \\
\hline
\end{tabular}

Table 4: BI-RADS category distribution of the study population

\begin{tabular}{lll}
\hline BI-RADS category & Frequency & Percentage \\
\hline 0 & 2 & 1.2 \\
1 & 75 & 45.2 \\
2 & 24 & 14.5 \\
3 & 30 & 18.1 \\
4 & 30 & 18.1 \\
5 & 5 & 3.0 \\
TOTAL & 166 & 100 \\
\hline
\end{tabular}

